\title{
BMJ Open Capturing the experience of the hospital-stay journey from admission to discharge using diaries completed by patients in their own words: a qualitative study
}

\author{
Craig S Webster, ${ }^{01,2}$ Tanisha Jowsey, ${ }^{1}$ Lucy M Lu, ${ }^{3}$ Marcus A Henning, ${ }^{1}$ \\ Antonia Verstappen, ${ }^{1}$ Andy Wearn, ${ }^{4}$ Papaarangi M Reid, ${ }^{5}$ Alan F Merry, ${ }^{2,6}$ \\ Jennifer M Weller ${ }^{1,6}$
}

To cite: Webster CS, Jowsey T, Lu LM, et al. Capturing the experience of the hospital-stay journey from admission to discharge using diaries completed by patients in their own words: a qualitative study. BMJ Open 2019;9:e027258. doi:10.1136/ bmjopen-2018-027258

- Prepublication history for this paper is available online. To view these files, please visit the journal online (http://dx.doi. org/10.1136/bmjopen-2018027258).

Received 14 October 2018 Revised 29 January 2019 Accepted 13 February 2019

Check for updates

(C) Author(s) (or their employer(s)) 2019. Re-use permitted under CC BY-NC. No commercial re-use. See rights and permissions. Published by BMJ.

For numbered affiliations see end of article.

Correspondence to Associate Professor Craig S Webster;

c.webster@auckland.ac.nz

\section{ABSTRACT}

Objective To capture and better understand patients' experience during their healthcare journey from hospital admission to discharge, and to identify patient suggestions for improvement.

Design Prospective, exploratory, qualitative study. Patients were asked to complete an unstructured written diary expressed in their own words, recording negative and positive experiences or anything else they considered noteworthy.

Participants and setting Patients undergoing vascular surgery in a metropolitan hospital.

Primary outcome measures Complete diary transcripts underwent a general inductive thematic analysis, and opportunities to improve the experience of care were identified and collated.

Results We recruited 113 patients in order to collect 80 completed diaries from 78 participants (a participant response rate of $69 \%$ ), recording patients' experiences of their hospital-stay journey. Participating patients were a median (range) age of 69 (21-99) years and diaries contained a median (range) of 197 (26-1672) words each. Study participants with a tertiary education wrote more in their diaries than those without-a median (range) of 353.5 (48-1672) vs 163 (26-1599) words, respectively (MannWhitney $\mathrm{U}$ test, $\mathrm{p}=0.001$ ). Three primary and eight secondary themes emerged from analysis of diary transcripts - primary themes being: (1) communication as central to care; (2) importance of feeling cared for and (3) environmental factors shaping experiences. In the great majority, participants reported positive experiences on the hospital ward. However, a set of 12 patient suggestions for improvement were identified, the majority of which could be addressed with little cost but result in substantial improvements in patient experience. Half of the 12 suggestions for improvement fell into primary theme 1, concerning opportunities to improve communication between healthcare providers and patients. Conclusions Unstructured diaries completed in a patient's own words appear to be an effective and simple approach to capture the hospital-stay experience from the patient's own perspective, and to identify opportunities for improvement.
Strengths and limitations of this study

- This study builds on previous work using healthcare diaries, but appears to be the first to capture the experience of the hospital-stay journey from the patient's perspective, by asking patients to complete an unstructured diary written in their own words.

- Our study recruited participants from a single vascular surgical hospital ward-such participants being purposively chosen to be those typically capable of completing a diary themselves for most of their hospital stay.

- We collected diaries from the same patient population during two time periods, 21 months apart, thus allowing us to assess the representativeness of our findings over time.

- Our study is consistent with the modern concept of Safety-II, in that it aimed to identify positive and negative patient experiences, thus offering opportunities to make good performance better, in addition to the elimination of the small number of remaining poor experiences.

\section{INTRODUCTION}

The quality and safety of aspects of healthcare remains of significant concern throughout the world, yet statistics alone on adverse events often fail to motivate the kinds of organisational change needed to bring about a threshold shift to a better quality of care. ${ }^{1-4}$ In 2000, the WHO's World Health Report recommended greater engagement with the patient experience in order to inform and improve the quality and safety of patient care. ${ }^{5}$ These recommendations have added momentum to the development of the patient-centred, and more recently, the person-centred healthcare paradigms. ${ }^{4-11}$ While scope for improvement certainly still exists in healthcare, for the vast majority of patients, care proceeds 
very well and research on patient safety has seen a real neglect of the opportunities for learning provided by these positive outcomes and experiences. ${ }^{12} 13$ Learning from what went right, in addition to what went wrong, is consistent with the modern concept of 'Safety-II', which focuses on making good performance better, in addition to attempting to eliminate the relatively small number of remaining adverse events that continue to occur. ${ }^{14}$

We also know that the patient's impressions of aspects of their care, particularly around the quality of communication, may be different to that of their care providers, regardless of the actual outcomes of the healthcare received by patients. ${ }^{815}$ Furthermore, despite the fact that patients in hospital spend the majority of their time on the ward, relatively little research that links patient experience with quality and safety has been conducted in this care environment. ${ }^{1617}$

Although diaries have been used in healthcare for some time, these have been used almost exclusively to collect information from a clinician's perspective (ie, for diagnostic, medication compliance and treatment-related purposes). ${ }^{18-20}$ Furthermore, healthcare diaries are often completed by health carers about patients, rather than by patients themselves. ${ }^{182122}$ We were unable to find any previous work using diaries completed by patients themselves to record the hospital-stay experience from a patient's own perspective. Our aim in the current study was therefore to capture and better understand patients' experience during their healthcare journey from hospital admission to discharge, as expressed in their own words in a written diary, and to identify patient suggestions for improvement.

\section{METHODS}

The concept and aims of the study were presented to clinical staff before the study began in order to anticipate potential problems in conducting the research, to introduce study personnel and invite nursing staff assistance in terms of the collection of completed diaries from patients.

\section{Patient and public involvement}

We used an exploratory mode of data collection in our study in order to better understand patient priorities by directly capturing the experiences and preferences of patients in their own words. Patients were not involved in the recruitment of participants to our study. However, as part of the informed consent process, participating patients were asked whether they would like to receive a summary of the findings of the study, and this was supplied in plain language at the study's completion. Presentations of the findings were also made to hospital ward staff in order that our results could benefit future patients.

\section{Participant recruitment}

All patients scheduled to undergo surgery in a vascular surgical ward were invited to participate. This patient population was selected purposively as one where study participants would typically be capable of continuing their diaries shortly after their surgery. Patients scheduled for transfer to another hospital or service were excluded. Each included patient was approached in their ward room by a researcher shortly after they had been admitted to hospital. The study was explained to them, and they gave written informed consent if they chose to participate. It was made clear to patients that involvement in the study did not take the place of complaints processes, which remained available to them during their hospital stay. Patients were provided with an information sheet summarising the aims of the study, which contained the contact information of study investigators, independent patient advocates and the institutional ethics committee in the event that patients had any concerns about the study during their involvement.

\section{Data collection and diary completion instructions}

Data collection was planned to occur at two distinct time points in order to determine whether the results of our study were stable over time, and was conducted by two research assistants (LML in period 1 and AV in period 2). Given some uncertainty around using diaries to capture the patient experience in the way we intended, we aimed to gather approximately double the number of diaries in each collection period as would typically be required to obtain thematic saturation with the use of interviewsnamely 40 diaries in each of the two time periods. ${ }^{23-25}$ After each patient had given informed consent to participate, self-reported demographics data were collected by the research assistant, including whether the participant had received a tertiary education, and a measurement of the emotional state of the participant using a self-reported $100 \mathrm{~mm}$ visual analogue scale with anchors of a sad face $(0 \mathrm{~mm})$ to happy face $(100 \mathrm{~mm}) \cdot{ }^{26}$ These demographics data were collected in order to describe the participant population and to determine whether emotional state or education level affected the ability of participants to complete dairies. Participants were provided with a pen and an A6 paper diary in which to record their hospital-stay experiences, and informed that they were free to complete their diary in their preferred written language. Participants were asked to record aspects of their hospital-stay experience that they perceived as positive or negative, in addition to anything else they considered noteworthy, and to record the date and time at which each entry was made. On leaving the ward, participants were asked to deposit their completed diaries in a drop box, or to hand the diary to a study researcher or ward nurse-thus completing study participation.

\section{Data analysis}

All completed diaries were transcribed verbatim, de-identified and transcripts loaded into QSR NVivo V.10 (QSR International, Melbourne, Australia). Qualitative analysis proceeded in two distinct stages. In the first stage, a general inductive approach was used to code sections of 
text of interest, consistent with the sensitising concepts of positive and negative experiences. ${ }^{27}{ }^{28}$ Codes were then grouped into themes in an iterative process, and checked for consistency and accuracy by senior research team members (CSW and TJ). In a further checking step, thematic coding was confirmed by an independent professional agency external to the research team (Academic Consulting, Auckland, New Zealand). Statistical testing was not performed on qualitative findings and supporting exemplar quotations are reported with pseudonyms. In the second stage of the qualitative analysis, diary transcripts were re-read in their entirety in order to identify specific instances of suggestions for improvement of the care experience made by patients, and details from these suggestions were collated. Our qualitative results have been reported in accordance with the Consolidated criteria for Reporting Qualitative research. ${ }^{29}$ Quantitative data were not normally distributed (Shapiro-Wilk test, $\mathrm{p}<0.01$ ), and so all comparisons were conducted with non-parametric tests using SPSS V.25 (IBM SPSS Statistics, Armonk, New York, USA).

\section{RESULTS}

In total, 171 patients were approached and invited to participate in the study, of which 113 elected to participate and gave written informed consent (a $66 \%$ response rate). In patients who gave a reason for declining to participate 13 were going home within the next day and thought that participation was not worthwhile, five felt unwell and three had trouble writing. In the 113 study participants, 78 returned a total of 80 completed diaries (a return rate of $69 \%$, given that two patients returned two diaries each). All returned diaries were completed in English. The first period of data collection ran from the 4 November 2011 to the 21 December 2011, in which data were collected full-time, 6 days a week-resulting in 42 completed diaries (table 1). The second period of data collection ran from 18 September 2013 to 12 November 2014, during which data were collected part-time, 1 day a week, resulting in the collection of 38 completed diaries.

Demographic and other data characteristics appeared indistinguishable between the two data collection periods, including self-reported patient ethnicity and emotional state, the number of words recorded in diaries and the number of participants with tertiary education (table 1 ). The distribution of the codes from which qualitative themes were built were also very similar between the two time periods (table 1 ).

On average, participants in our study were in a relatively happy emotional state, with a median (range) visual analogue score of $74(0-100)$, showing the majority of scores at the 'happy face' end of the scale. There was no significant correlation between emotional state and number of words recorded in patients' diaries (Spearman's rho $=-0.145$, n.s.). There was also no significant difference seen in the number of words recorded in patients' diaries according to gender-median (range) words for male and female study participants being 184 (28-1672) words vs 209 (26-1201), respectively (MannWhitney $\mathrm{U}$ test, $\mathrm{p}=0.99$, n.s.). However, study participants with a tertiary education wrote significantly more in their patient diaries than did those without a tertiary education-median (range) of 353.5 (48-1672) words vs 163 (26-1599), respectively (Mann-Whitney $\mathrm{U}$ test, $\mathrm{p}=0.001$ ).

The great majority of patients reported a very positive experience on the hospital ward, for which they were grateful:

To be honest overall I am staggered at the high quality of care offered at a public hospital and I am very grateful, [the team] were amazing (David, 44 years).

Three primary and eight secondary themes emerged from the inductive qualitative analysis and are reported with exemplar quotations in table 2.

Table 1 Demographics and time periods

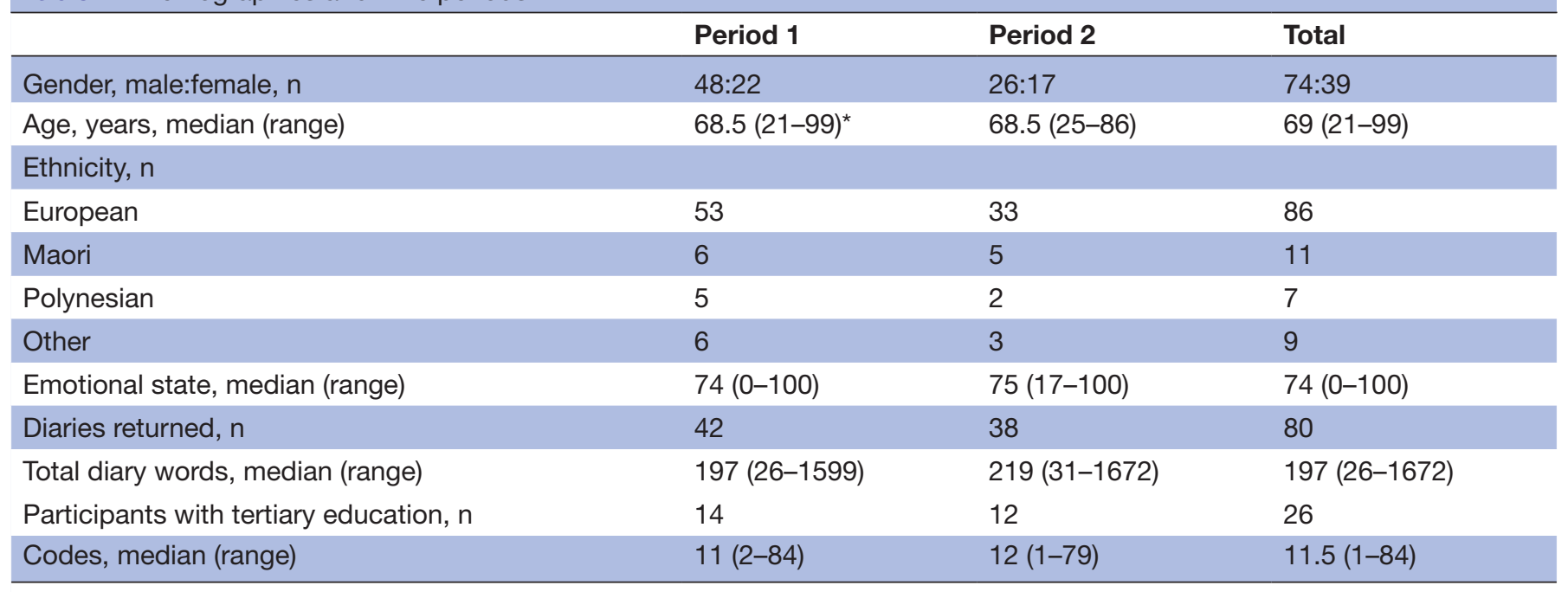

${ }^{*}$ One patient aged 99 years elected to participate by dictating diary entries to her son. 
Table 2 Primary and secondary themes to emerge from qualitative analysis with exemplar quotations

\section{Primary theme Secondary theme}

1. Communication a. Explanations of what to expect

as central to care A full explanation [was] provided to wife and self in layman's terms (Bob, 62 years).

Had surgical team around-all going well-good explanation regarding plans for the future (Vaughan,

78 years).

When I woke up 2-1-2014 I was mortified to find my right leg had been cut from groin to halfway down my leg. Nothing of this magnitude had been communicated to me. Talk was of groin blockage (Molly, 72 years). The team arrived, stared and looked generally uninterested. Doctor asked usual questions and responded to mine, but all had vanished before I could ask the next question. It's all superficial and pointless (William, 67 years).

MRI went well, when we eventually got there at $8 \mathrm{pm}$. My apprehension was possibly because of lack of explanation. If I ever need one again it will be no big deal. Maybe a more detailed explanation would help people relax before the procedure (Cooper, 78 years).

...I can go home... Thrombosis educator spent ages with me and was excellent-clear, patient and caring. I feel very confident about my ongoing treatment (Mary, 37 years).

b. Patient feeling included and heard

I had a meeting with [the] anaesthetist which was very helpful and he really listened to me. He explained thoroughly the procedure, etc, and I felt much more comfortable about having anaesthetic, as was a bit nervous about it seeing [that] I have emphysema (Lillian, 75 years).

Reflected on past 2 weeks. Many discussions with doctors over past 10 days. All friendly, informative and courteous. The type of questions I asked the doctors were all health related. What's wrong? What effect does it have? How do we fix it? How long will it take? At all times every question I asked was adequately answered with positive explanations of what was happening (Sebastian, 63years).

\section{c. Patient position and power}

I like the way two doctors talk beside you so that you feel included in the conversation (Sabine, 81 years). Sometimes when lots of docs are in my room they just talk to each other and not always to me (Hemi, 67 years).

I refer here to the team of surgeons/doctors/nurses who do daily patient visits. While I think they are trying to be inclusive, often there is dialogue between team members with the substance not necessarily being passed on to the patient. Even after the frequency of my hospital stays I find it quite difficult on occasions to pose questions or matters of concern. Partly I think this is because of the subordinate position of the patient (lying down while team are all standing) (Felix, 69 years).

You are lying flat on your back in an unfamiliar bed environment when a 'team' of clearly very important and distinguished people descends to STARE at you. Occasionally, you are asked a question by a group member without identifying him or herself in any way. Usually no labels, identification, etc. While you answer as best as you can you are left mystified about who you are responding to and the relevance of your answer. While acknowledging the obvious skill experience professional competence you wish to help both yourself and the whole organisation but you still don't know who the bloody person is that you are talking to!!! (lan, 73years).

2. Importance of feeling cared for

\section{a. Pain management}

I had been to sleep late last night as my legs were painful. They were painful again this morning as the magnesium salt dressings were biting away at my legs (Hannah, 81 years).

[I] had a restless night. My legs were very painful had to get out of bed and go for a walk to the TV room (day 1)... I had a good night no pain whatever they gave me worked very well (Ngiare, 70 years, day 2). Sometimes there is too much rush because doctors are coming to see you. Nurses start working at 10 times [their usual] speed. In [the] process they cause too much pain especially with bandages being pulled out (Jim, 56 years).

They send me back for angio and they can't put me to sleep. It's a big risk because of my heart and that I can't lie on my back because of the pain on my crack rib. So the guy has to stay close to give some more higher bigger pain killer to help me with my pain while the doctor was doing to angio (Talia, 61 years).

\section{b. Characteristics of HCP staff}

Also senior dermatologist who is treating a rash on my face showed me that the cause was not as bad as I had originally thought and the cure was quite achievable. He was very approachable and kind (Sabine, 81 years).

The nursing staff in the ward in the main were excellent-efficient, caring, gentle, knowledgeable, kind and all smiles. However, unfortunately there were one or two other nurses whose lack of compassion and abruptness of manner made me wonder why they were nurses at all-perhaps to them it is just a job!!! (Hank, 79 years).

Nursing staff all caring and very helpful and willing to provide the smallest request (Grace, 78years). 
Table 2 Continued

\begin{tabular}{|c|c|}
\hline Primary theme & Secondary theme \\
\hline $\begin{array}{l}\text { 3. Environmental } \\
\text { factors } \\
\text { shaping patient } \\
\text { experiences }\end{array}$ & 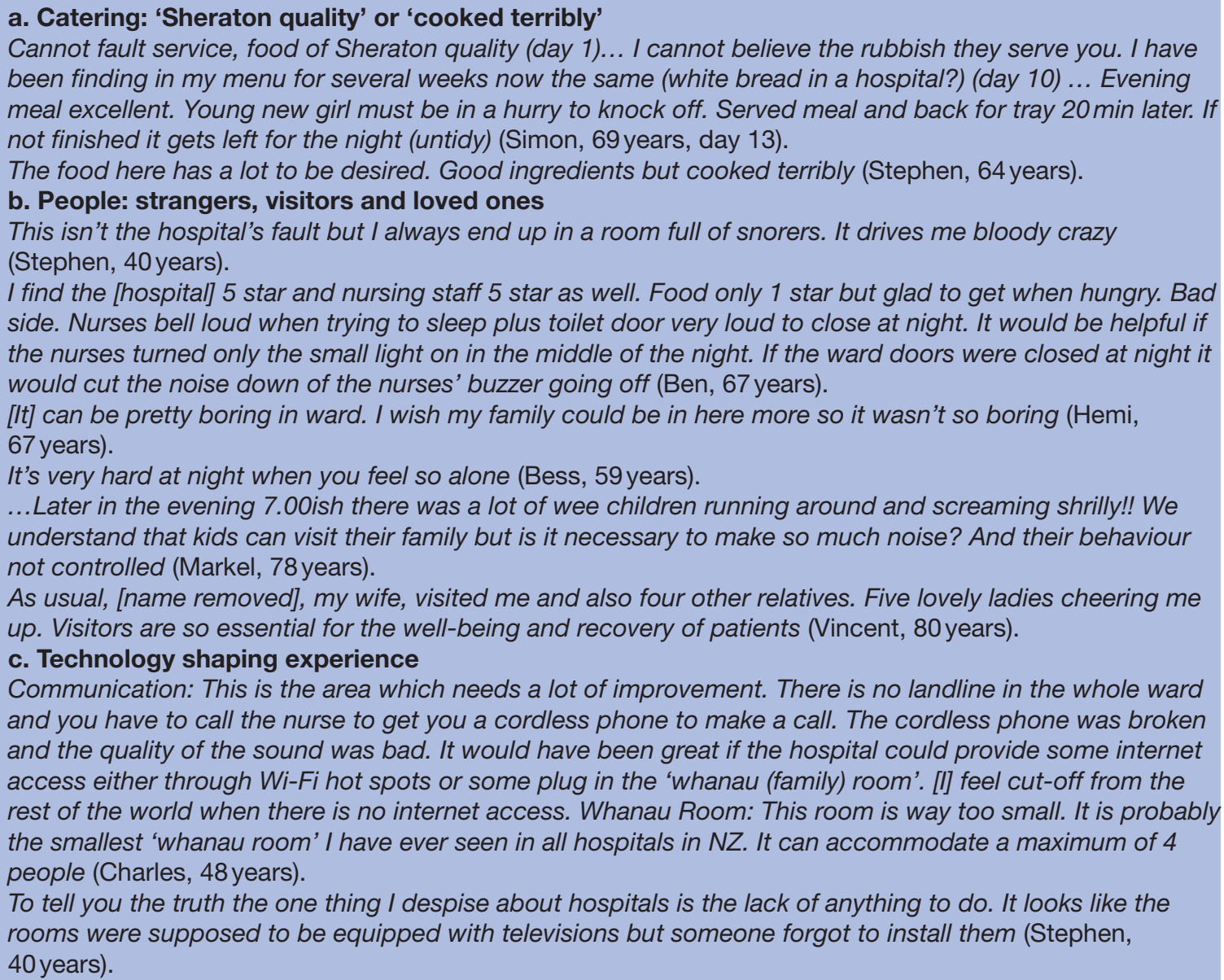 \\
\hline
\end{tabular}

\section{Communication as central to care}

In many cases, the main driving factor behind whether participants deemed their experiences as positive or negative centred around communication and interactions with healthcare providers (HCPs), how information was conveyed (or not) to the patient and how accessible HCPs made themselves to the patient and/or the patient's family. Positive comments greatly outnumbered negative ones. However, participants often reported not being told that their medications or care plan had been changed, or that they had finished their current medication prescription. Participants also reported specific circumstances where communication was poor between HCPs and patients, for example, in patients with hearing or sight impairment.

\section{Explanations of what to expect}

Many patients were pleased with the explanations given to them and their family about upcoming procedures. However, some reported that they were provided with limited information, given poor explanations of their health status and of upcoming procedures or felt that they were not listened to. Patients suggested that having more details explained to them ahead of time would substantially reduce their anxiety about unfamiliar upcoming procedures (table 2, section 1a).

Communication was considered particularly important on discharge in order that patients would know what to expect during their recovery and in order to allow them to continue with any needed medications (table 2 , section 1a-Mary).

\section{Patient feeling included and heard}

Participants identified that their feeling of inclusion in decision-making and of being 'heard' by HCPs substantially determined their overall experience, with real potential to reduce patient anxiety if done well (table 2, section $1 b)$.

\section{Patient position and power}

Patients reported that at times HCPs would discuss their case with other HCPs in front of them (but without directly including them in the conversation). Patients interpreted this in one of two ways, they either saw it as inclusive by way of HCPs having a conversation within hearing distance, or they interpreted it as excluding them from conversation (with the implication that this was impolite). These different perspectives of similar events 
illustrate the subjective nature of healthcare encounters, and the importance of confirming with patients that they feel included in-and are satisfied with-an encounter.

Two patients suggested that their feeling of inclusion and power to pose their questions to HCPs was partially determined by people's positions and locations in the room, in the sense that patients may feel subordinate because they are lying down, while HCPs are standing over them (tables 2 , section 1c-Felix and Ian). Hence, despite the efforts of HCPs to include patients in conversations concerning their care, some patients felt that their power and agency were mitigated to some degree by their 'subordinate position' of lying in bed.

\section{Importance of feeling cared for}

Participants appreciated it when HCPs demonstrated that they cared for them during their communications and through their actions-this commonly involved HCPs attending to some aspect of the patient's personal comfort during the interaction.

\section{Pain management}

Episodes of pain related to their condition were often described by patients in their diaries. Participants described the types of pain, levels of pain, their own efforts to manage pain and the efforts of HCPs to manage it. The management of pain was central to patient's feelings of being cared for (table 2, section 2a).

\section{Characteristics of HCP staff}

In describing characteristics of HCPs that made patients feel cared for, patients often used terms such as 'approachable', 'kind', 'smiles', 'gentle' and 'helpful'. Although few diaries contained negative feedback on the conduct or attitude of different hospital staff, such accounts, when they did occur, left participants feeling uncared for (table 2, section 2b-Hank).

\section{Environmental factors shaping patient experiences}

Aspects of the hospital environment featured in just over half of patient diaries, indicating that participants viewed it as influential in shaping their experiences. For the many who provided positive feedback concerning the hospital environment, aspects that they highlighted included levels of cleanliness, the quiet atmosphere within the ward and the friendliness of staff. While many comments highlighted specific aspects of the environment as having a negative or positive influence on their experience, other comments pointed to broader issues of how the hospital environment limited their movement, robbed them of the capacity to 'do' anything with their time, reduced their sense of social connection and disrupted their sense of autonomy, privacy or comfort.

\section{Catering: 'Sheraton quality' or 'cooked terribly'}

The quality of food was a relatively common topic that patients reported on, but a range of views were evident. Some patients reported that the catering quality was of an adequate, or even high standard, compared with other hospitals they had been in. Other patients were more critical of the catering quality (table 2 , section $3 a$ ).

\section{People: strangers, visitors and loved ones}

Patients in this study were in a hospital ward where they shared a room with other patients whom they did not know. They were allowed visitors (family and friends) during specific visiting hours and they had access to a Whanau (family) Room on the ward. Sharing the space with strangers was often reported as having negative implications, such as lack of privacy during consultations and noise when participants wanted quiet, for example, when attempting to sleep.

The constraints of the environment-lack of Wi-Fi access or television, or other comforts of home including loved ones-often left participants feeling bored and lonely. However, some participants suggested that having other patients in their ward room could also be positive in terms of having someone to chat with and pass the time with (table 2, section 3b). Similarly, a number wrote about visitors to the ward; either to visit themselves (which were usually linked with positive associations), or other patients (which were sometimes viewed more negatively).

\section{Technology shaping experience}

Participants described the impact of the environment on their experiences in terms of their access to technology (telephones, Wi-Fi and television). The value of access to technology was framed in terms of patients feeling both a sense of social connection and of entertainment.

\section{Patient recommendations for improved service delivery and patient experience}

From the second stage of the qualitative analysis, 12 problem areas with the hospital experience were identified. These are shown in table 3 along with the potential solutions proposed by patients, and ordered by the primary theme category for each. Suggestions for improvement were most commonly associated with primary theme number 1 -communication as central to care ( 6 of 12 suggestions), followed by primary theme number 3 -environmental factors shaping patient experience ( 5 of 12 suggestions).

\section{DISCUSSION}

Eighty completed diaries recording the negative and positive experiences of patients during their hospital stay were collected, each containing a median (range) of 197 (26-1672) words. Experiences reported in diaries were in the great majority positive. Three primary themes emerged from diaries, these being: (1) communication as central to care; (2) importance of feeling cared for and (3) environmental factors shaping experiences. Twelve problem areas were also identified by a minority of patients with proposed solutions- 6 of 12 of these problem areas involved aspects of communication between HCPs and patients. 
Table 3 Problem areas identified from diaries with proposed solutions

\begin{tabular}{|c|c|c|c|}
\hline $\begin{array}{l}\text { Problem identified by } \\
\text { patients }\end{array}$ & $\begin{array}{l}\text { Corresponding primary } \\
\text { theme }\end{array}$ & Details & $\begin{array}{l}\text { Specific improvements } \\
\text { proposed by patients }\end{array}$ \\
\hline
\end{tabular}

1. Communication around 1 (Communication as procedure planning central to care)
Patient did not understand the procedure the scheduling office wanted to bring them in for, and so refused it-better explained later by surgeon

\section{Delays and scheduling 1} difficulties

\section{Communication with 1} outside world

4. Communicating with a 1 crowd of doctors
Waiting for hours in a strange area of the hospital for a scan, or worse, for surgery when nil by mouth, can be distressing to be made outside of the Auckland region

During ward rounds or other times, it is hard to know who is who, and
Scheduling office needs to have a better understanding of technical language so they can explain procedures better on the phone

Better communication with patients on what is happening with their care

Ward phone does not allow toll calls Remove toll bar to ask questions when there are many doctors at once by bedside

Patients not told that their medications or care plan had been changed, or that they had finished their current medication prescription

$\begin{array}{ll}\begin{array}{l}\text { 5. Changes in medications } 1 \\ \text { or care plans not }\end{array} & \begin{array}{l}\text { Patients not told that their } \\ \text { medications or care plan had } \\ \text { communicated to patient }\end{array} \\ \begin{array}{l}\text { been changed, or that they had } \\ \text { finished their current medication } \\ \text { prescription }\end{array}\end{array}$

6. Problems with discharge 1

of patients from ward

It can take many hours for paperwork to be signed off even though the patient is ready to go home. Pain management of patient at discharge is also important

$\begin{array}{ll}\text { 7. Caring for patients with } & 2 \text { (Importance of feeling } \\ \text { specific disabilities } & \text { cared for) }\end{array}$
Blind or deaf patients were sometimes treated in a way that made it clear that staff did not know of the patient's disability

8. Meals sometimes too large

3 (Environmental factors shaping patient experiences)

9. Difficulties for out-of-town 3
patients
9. Difficultie
patients 3

10. Mixed-gender ward 3 rooms were disliked

$\begin{aligned} & \text { 11. Difficulties sleeping at } \\ & \text { night }\end{aligned}$
$\begin{aligned} & \text { 12. Boredom in ward } \\ & \end{aligned}$

\section{3}

Patient was not able to finish any of A small-meal option would be her meals

Accommodation and parking are expensive. Some assistance is available to out-of-town patients for these costs but no one tells you about it

\section{Can be uncomfortable or} embarrassing to have one young female in same ward room as three older men

\section{Loud noises in ward and bright} lights keep patients awake

Nothing to do for many hours, particularly in private rooms useful

A one-on-one consultation with patient at key points during care would make communication easier for patient

Make informing the patient part of the process for making changes in care plans or prescriptions

Paperwork could be prepared in advance to save time. Assess all patients for pain before discharge and give appropriate prescriptions

\section{patient's disabilities}

Proactive, targeted assistance for out-of-town patients Better awareness in staff of
A limitation of this study is that it was conducted in a single vascular surgical ward. However, the stability of the data characteristics and findings across the two study time periods, 21 months apart, suggests that our results are representative of the patient population from which they are drawn-and this is despite full-time versus part-time data collection. Furthermore, our findings appear to be congruent with other large-scale quantitative studies on the patient experience (discussed below). We purposively chose a population of patients for our study who were able to complete a diary themselves for most of their hospital stay. However, composite diaries could be kept 
in other patient populations where care providers or family members make entries during the periods of care where the patient is not able to make diary entries themselves (as is often done with patients in the intensive care unit). ${ }^{22}$ The completion of diaries by patients appears to be a simple and intuitive method of capturing the patient experience which patients appear to engage with, and so this approach could easily be extended to other healthcare domains. ${ }^{12}{ }^{30}$ The use of questionnaires to assess patient satisfaction with healthcare clearly has its place, and questionnaire data are generally considered to be simpler and faster to summarise than the qualitative data yielded by unstructured diaries. However, rapid methods of analysis of qualitative data are available. ${ }^{31}$ In addition, questionnaires come with their own frame of reference, since the questions are predetermined, and do not lend themselves to the capture of individual narratives. Questionnaires can be used only after it is known which questions are meaningful or important to ask. In fact, among its other uses, an unstructured diary approach can guide question and questionnaire selection in subsequent work. Ultimately, the most appropriate data collection method will be determined by the aims of any particular study, as each approach has its own strengths and limitations. ${ }^{18}$

In recent years, the value of patient experience and feedback as an important source of data on the quality and safety of healthcare provision has become more widely appreciated, including in a number of large-scale studies. In a systematic review of 55 published studies considering patient-centred care and outcomes, consistent positive associations were seen between measures of patient experience, patient safety and the effectiveness of healthcare in a wide range of diseases, settings and outcome measures. ${ }^{32}$ In a 13-country study of 61168 nurses and 131318 patients, the reported quality of the hospital environment was significantly associated with patient satisfaction, and the quality and safety of patient care. More specifically, in a study of 2249 patients using the Picker Patient Experience Questionnaire, a validated survey instrument used internationally, almost $90 \%$ of respondents were found to be satisfied with their period of inpatient care, and the results of a multiple linear regression indicated the major determinants of patient satisfaction were physical comfort, emotional support and respect for patient preferences. ${ }^{33}$ It has also been known for some time that malpractice claims against HCPs are more likely when patients believe communication about their care was poor, rushed or inadequate and when HCPs devalue the patients' views-thus further emphasising the importance of considerations of communication and the patients' perspective during healthcare..$^{34} 35$ The above findings are consistent with the qualitative findings of the present study in the sense that the great majority of patients returning a diary were satisfied with their care and that the three emergent primary themes of our study address many of the same issues as those identified as the determinants of patient satisfaction, including the leading importance of communication.
Although variable amounts of text were recorded in diaries in our study, the overall participant response rate of $69 \%$ was considerably higher than other paper-based patient diary studies where diaries were used for diagnostic or treatment-related purposes. ${ }^{36}{ }^{37}$ Reasons for the relatively high participant response rate in the current study are likely related to the nature of the data recorded in diaries and the way in which we asked patients to use their diaries. In previous healthcare diary studies patients are typically expected to make entries at regular, designated time periods and about specific events or physiological variables, that is, to make diary entries determined by the clinician's perspective. In these circumstances, patient compliance with the use of a paper diary is generally poor. ${ }^{37-39}$ Our study, by contrast, had a very different aim-we wished to capture the hospital-stay experience from the patient's perspective and in their own words. We did not require entries to be made at specific times, but asked patients to record anything which was important to them whenever they wished (thus minimising retrospective recall bias, a common limitation with questionnaires). The events recorded in diaries often formed personal narratives, hence making it more likely that patients would complete diaries. ${ }^{70}$ Our findings suggest that the use of unstructured written diaries completed by patients can be a practical and useful measure of patient experience.

In our study, the two largest influencing factors of the patient experience were the effectiveness of communication with HCPs, and environmental factors in the hospital ward-both being strongly reflected in patient suggestions for improvement, thus emphasising the scope for co-design of aspects of care in hospital (table 3). ${ }^{41}$ For example, poor communication about a patient's care was associated with feelings of frustration, being uncared for and confusion about what to expect next. However, this was not the case when care changes were made, but where these were effectively communicated to the patient. In particular, effective communication is important in preventing medication adverse events when changes are made to a patient's medication-with one study of 2471 hospital inpatients indicating that medication adverse events are the most common type of safety incident reported by patients. ${ }^{13}$ Similarly, discharge procedures were identified as an important opportunity for coordinated communication with the patient (table 3 ). Others have shown that revisions to the discharge procedures intended to make the process more patient-centred and to highlight follow-up requirements, can significantly improve patient experience and satisfaction with discharge. ${ }^{42}{ }^{43}$ In addition, a number of environmental factors highlighted by patients could be remedied with little cost and effort (table 3). For example, the importance of efforts to promote sleep at night by closing doors to reduce noise and dimming lights is supported by research showing the substantial contribution of sleep to healing and patient well-being. ${ }^{445}$

Our results also contained diary entries from two patients who independently identified themselves as being 
in inferior power relationships with their HCPs, through their position of lying down in their hospital bed (table 2, section 1c). This power relationship can be ameliorated simply by the HCP sitting down before conversing with the patient. In a study of 120 patients on a neurosurgery ward, patients perceived consultations with their HCPs to be more positive, informative and to last longer when HCPs sat down before a conversation, even when consultations were of the same length of time. ${ }^{46}$

\section{CONCLUSION}

Unstructured hospital-stay diaries completed by patients appear to be a relevant and valid method for the assessment of patient experience. Our study demonstrated that the hospital-stay experience for the great majority of patients was a positive one, and allowed a better understanding of this experience, in the form of insights in three primary, and eight secondary themes. Twelve areas for potential improvement of the care experience were also identified by a minority of patients, these primarily being concerned with communication with their HCPs and with certain aspects of the hospital ward environment. Potential solutions to a number of the identified areas of concern are known, suggesting that many can be remedied with little cost or effort, but with substantial returns in improved patient experience.

\section{Author affiliations}

${ }^{1}$ Centre for Medical and Health Sciences Education, University of Auckland, Auckland, New Zealand

${ }^{2}$ Department of Anaesthesiology, University of Auckland, Auckland, New Zealand ${ }^{3}$ Department of Ophthalmology, University of Auckland, Auckland, New Zealand ${ }^{4}$ Medical Programme Directorate, University of Auckland, Auckland, New Zealand

${ }^{5}$ Te Kupenga Hauora Māori, University of Auckland, Auckland, New Zealand

${ }^{6}$ Department of Anaesthesia, Auckland City Hospital, Auckland, New Zealand

Acknowledgements The authors would like to thank Mr Russell Bourchier, Mr Andrew Hill, Kara Hamilton, institutional patient advisors and other staff at Auckland City Hospital, New Zealand, for supporting this study. The authors would also like to thank Dr Lyn Lavery and Academic Consulting, Auckland, New Zealand, for conducting the external coding check of our qualitative analysis, and to Dr Denys Court of the Medical Protection Society of New Zealand for advice on the medicolegal status of the information recorded in patient diaries.

Contributors CSW conceived of the study and is guarantor. The study was designed with contributions from CSW, JMW, MAH, PMR, AW and AFM. Primary data collection and assistance with analysis was undertaken by LML and AV. CSW and TJ conducted the data analysis. CSW, TJ and JMW revised the manuscript with contributions from other authors. All authors approved of the final version of the manuscript for publication.

Funding This project was supported by a grant from the Faculty Research Development Fund, Faculty of Medical and Health Sciences, University of Auckland, New Zealand, grant number 3702377 , and by a summer studentship stipend to LML from the Faculty of Medical and Health Sciences, University of Auckland, New Zealand.

Competing interests CSW and AFM own shares in SAFERsleep (London, UK), a company that aims to improve safety in healthcare.

Patient consent for publication Not required.

Ethics approval This study was conducted in a vascular surgical ward at Auckland City Hospital with the approval of clinical team leaders, the hospital research office and the regional ethics committee (Health and Disability Ethics Committee, ref. 13/ CEN/80).
Provenance and peer review Not commissioned; externally peer reviewed.

Data sharing statement Consistent with our institution's ethics approval, no additional data are available.

Open access This is an open access article distributed in accordance with the Creative Commons Attribution Non Commercial (CC BY-NC 4.0) license, which permits others to distribute, remix, adapt, build upon this work non-commercially, and license their derivative works on different terms, provided the original work is properly cited, appropriate credit is given, any changes made indicated, and the use is non-commercial. See: http://creativecommons.org/licenses/by-nc/4.0/.

\section{REFERENCES}

1. Institute of Medicine. To err is human: building a safer health system. Washington DC: National Academy Press, 2000.

2. Department of Health. An Organisation With A Memory - Report Of An Expert Group On Learning From Adverse Events In The NHS. London: Stationery Office, 2000.

3. Davis P, Lay-Yee R, Schug S, et al. Adverse events in New Zealand public hospitals - principal findings from a national survey. Wellington: Ministry of Health, 2001.

4. Webster CS. Checklists, cognitive aids, and the future of patient safety. Br J Anaesth 2017;119:178-81.

5. World Health Organisation. The World Health Organisation Report health systems: improving performance. Geneva, Switzerland: World Health Organisation, 2000.

6. Mead N, Bower P. Patient-centredness: a conceptual framework and review of the empirical literature. Soc Sci Med 2000;51:1087-110.

7. Wagner EH, Bennett SM, Austin BT, et al. Finding common ground: patient-centeredness and evidence-based chronic illness care. $J$ Altern Complement Med 2005;11(Suppl 1):s7-15.

8. Groene O, Sunol R, Klazinga NS, et al. Involvement of patients or their representatives in quality management functions in EU hospitals: implementation and impact on patient-centred care strategies. Int J Qual Health Care 2014;26(Suppl 1):81-91.

9. Richards T, Coulter A, Wicks P. Time to deliver patient centred care. BMJ 2015;350:h530.

10. Beutow S. Person-centred health care - balancing the welfare of clinicians and patients. New York: Routledge, 2016.

11. McCormack B, Manley K, Walsh K. Person-centred systems and processes. In: Manley K, McCormack B, Wilson V, eds. International practice development in nursing and healthcare. Oxford: Blackwell, 2009.

12. El-Farargy N, Walker G. A Line of Defence: Using Stories in Healthcare Education. Med Sci Educ 2017;27:805-14.

13. O'Hara JK, Reynolds C, Moore S, et al. What can patients tell us about the quality and safety of hospital care? Findings from a UK multicentre survey study. BMJ Qual Saf 2018;27:673-82.

14. Hollnagel E. Safety-I and Safety-II - the past and future of safety management. Boca Raton, FL: CRC Press, 2014.

15. Kennedy BM, Rehman M, Johnson WD, et al. Healthcare providers versus patients' understanding of health beliefs and values. Patient Exp J 2017;4:29-37.

16. Maben J, Griffiths P, Penfold C, et al. One size fits all? Mixed methods evaluation of the impact of $100 \%$ single-room accommodation on staff and patient experience, safety and costs. BMJ Qual Saf 2016;25:241-56.

17. Webster CS, Anderson DJ. A practical guide to the implementation of an effective incident reporting scheme to reduce medication error on the hospital ward. Int J Nurs Pract 2002;8:176-83.

18. Verbrugge LM. Health diaries. Med Care 1980;18:73-95.

19. Blair KTA, Eccleston SD, Binder HM, et al. Improving the patient experience by implementing an ICU diary for those at risk of postintensive care syndrome. J Patient Exp 2017;4:4-9.

20. van Berge Henegouwen MT, van Driel HF, Kasteleijn-Nolst Trenité DG. A patient diary as a tool to improve medicine compliance. Pharm World Sci 1999;21:21-4.

21. Roulin MJ, Hurst S, Spirig R. Diaries written for ICU patients. Qual Health Res 2007;17:893-901.

22. Egerod I, Storli SL, Åkerman E. Intensive care patient diaries in Scandinavia: a comparative study of emergence and evolution. Nurs Inq 2011;18:235-46.

23. Geertz C. Thick description: towards an interpretive theory of culture. In: Lincoln YS, Denzin NK, eds. Turning Points in Qualitative research: tying knots in a handkerchief. Walnut Creek, CA: AltaMira Press, 1973.

24. Guest G, Bunce A, Johnson L. How many interviews are enough? An experiment with data saturation and variability. Field Methods 2006;18:59-82. 
25. Francis JJ, Johnston M, Robertson C, et al. What is an adequate sample size? Operationalising data saturation for theory-based interview studies. Psychol Health 2010;25:1229-45.

26. Wewers ME, Lowe NK. A critical review of visual analogue scales in the measurement of clinical phenomena. Res Nurs Health 1990;13:227-36.

27. Thomas DR. A general inductive approach for analyzing qualitative evaluation data. Am J Eval 2006;27:237-46.

28. Saldaña J. The coding manual for qualitative researchers. London: Sage, 2013.

29. Tong A, Sainsbury P, Craig J. Consolidated criteria for reporting qualitative research (COREQ): a 32-item checklist for interviews and focus groups. Int J Qual Health Care 2007;19:349-57.

30. Webster CS, Lu LM, Henning MA. Using hospital-stay diaries to improve communication with patients. Med Educ 2014;48:533-4.

31. Taylor B, Henshall C, Kenyon S, et al. Can rapid approaches to qualitative analysis deliver timely, valid findings to clinical leaders? A mixed methods study comparing rapid and thematic analysis. BMJ Open 2018;8:e019993.

32. Doyle C, Lennox L, Bell D. A systematic review of evidence on the links between patient experience and clinical safety and effectiveness. BMJ Open 2013;3:e001570.

33. Jenkinson C, Coulter A, Bruster S, et al. Patients' experiences and satisfaction with health care: results of a questionnaire study of specific aspects of care. Qual Saf Health Care 2002;11:335-9.

34. Hickson GB, Federspiel CF, Pichert JW, et al. Patient complaints and malpractice risk. JAMA 2002;287:2951-7.

35. Levinson W. Physician-patient communication. A key to malpractice prevention. JAMA 1994;272:1619-20.
36. Hufford MR, Stokes TE, Paty JA. Collecting reliable and valid realtime patient experience data. Drug Inf J 2001;35:755-65.

37. Stone AA, Shiffman S, Schwartz JE, et al. Patient non-compliance with paper diaries. BMJ 2002;324:1193-4.

38. Given JE, O'Kane MJ, Bunting BP, et al. Comparing patientgenerated blood glucose diary records with meter memory in diabetes: a systematic review. Diabet Med 2013;30:901-13.

39. Shea HE, Preston C, Hudson S. Electronic patient diaries in a clinical trial-the holistic approach. Drug Inf J 2004;38:225-38.

40. Holloway I, Freshwater D. Narrative research in nursing. Blackwell: Oxford, 2007.

41. Health Service Co-design. http://www.healthcodesign.org.nz/ (Accessed 27 Jan 2019).

42. Waniga HM, Gerke T, Shoemaker A, et al. The impact of revised discharge instructions on patient satisfaction. J Patient Exp 2016;3:64-8.

43. Finefrock D, Patel S, Zodda D, et al. Patient-centered communication behaviors that correlate with higher patient satisfaction scores. $J$ Patient Exp 2018;5:231-5.

44. Knutson KL, Ryden AM, Mander BA, et al. Role of sleep duration and quality in the risk and severity of type 2 diabetes mellitus. Arch Intern Med 2006;166:1768-74.

45. Blackwell T, Yaffe K, Ancoli-Israel S, et al. Poor sleep is associated with impaired cognitive function in older women: the study of osteoporotic fractures. J Gerontol A Biol Sci Med Sci 2006;61:405-10.

46. Swayden KJ, Anderson KK, Connelly LM, et al. Effect of sitting vs. standing on perception of provider time at bedside: a pilot study. Patient Educ Couns 2012;86:166-71. 